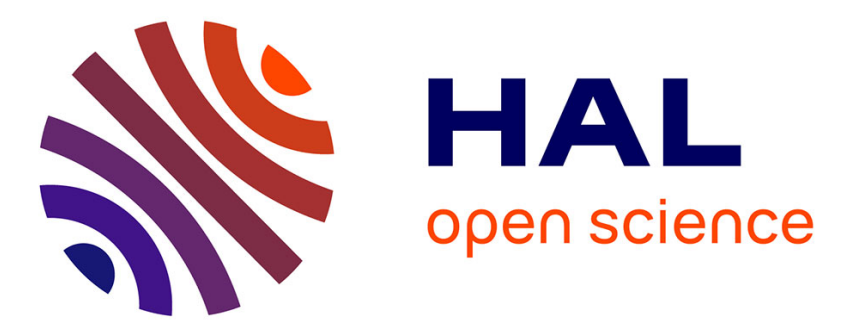

\title{
Demographic responses to mercury exposure in two closely-related Antarctic top predators
}

Aurélie Goutte, Paco Bustamante, Christophe Barbraud, Henri Weimerskirch, Karine Delord, Olivier Chastel

\section{- To cite this version:}

Aurélie Goutte, Paco Bustamante, Christophe Barbraud, Henri Weimerskirch, Karine Delord, et al.. Demographic responses to mercury exposure in two closely-related Antarctic top predators. Ecology, 2014, 95 (4), pp.1075-1086. 10.1890/13-1229.1 . hal-00983249

\section{HAL Id: hal-00983249 \\ https://hal.science/hal-00983249}

Submitted on 24 Apr 2014

HAL is a multi-disciplinary open access archive for the deposit and dissemination of scientific research documents, whether they are published or not. The documents may come from teaching and research institutions in France or abroad, or from public or private research centers.
L'archive ouverte pluridisciplinaire HAL, est destinée au dépôt et à la diffusion de documents scientifiques de niveau recherche, publiés ou non, émanant des établissements d'enseignement et de recherche français ou étrangers, des laboratoires publics ou privés. 


\section{Demographic responses to mercury exposure in two closely-related Antarctic top predators}

Goutte A. ${ }^{1}$, Bustamante P. ${ }^{2}$, Barbraud C. ${ }^{1}$, Delord K. ${ }^{1}$, Weimerskirch H. ${ }^{1}$, Chastel O. ${ }^{1}$

${ }^{1}$ Centre d'Etudes Biologiques de Chizé (CEBC), UPR 1934-CNRS, F-79360, France

${ }^{2}$ Littoral Environnement Société (LIENSs), UMR 7266-CNRS, Université de La Rochelle, 2 rue Olympe de Gouges, F-17000, France

Correspondence: Aurélie Goutte, goutte@ cebc.cnrs.fr 


\section{ABSTRACT}

Although toxic chemicals constitute a major threat for wildlife, their effects have been mainly assessed at the individual level and under laboratory conditions. Predicting population-level responses to pollutants in natural conditions is a major and ultimate task in ecological and ecotoxicological research. The present study aims to estimate the effect of mercury $(\mathrm{Hg})$ levels on future apparent survival rates and breeding performances. We used long-term data set (ca. 10 years) and recently-developed methodological tools on two closely-related Antarctic top predators, the south polar skua Catharacta maccormicki from Adélie Land and the brown skua C. lonnbergi from the Kerguelen archipelago. Adult survival rates and breeding probabilities were not affected by $\mathrm{Hg}$ levels, while breeding success the following year decreased with increasing $\mathrm{Hg}$ levels. Although south polar skuas exhibited much lower Hg levels than brown skuas, they suffered from higher Hg-induced breeding failure. This species-difference could be attributed to an interaction between $\mathrm{Hg}$ and other environmental perturbations, including climate change and complex cocktail of pollutants. By including $\mathrm{Hg}$-dependent demographic parameters in population models, we showed a weak population decline in response to increasing $\mathrm{Hg}$ levels. This demographic decline was more pronounced in south polar skuas than in brown skuas. Hence Hg exposure differently affects closely-related species. The wide range of environmental perturbations in Antarctic regions could exacerbate the demographic responses to $\mathrm{Hg}$ levels. In that respect, we urge future population modeling to take into account the coupled effects of climate change and anthropogenic pollutions to estimate population projections.

Key words: brown skua, south polar skua, capture-recapture, heavy metals, Southern Ocean, pollution, survival, reproductive performance, population dynamics, population projections. 


\section{INTRODUCTION}

A major challenge in ecological research is to assess and predict the ecological impact of environmental changes on demographic traits and on population dynamics. In that respect, a large amount of studies have evidenced steep population declines and high extinction risks in response to ongoing climate change (Thomas et al. 2004; Frederiksen et al. 2004, Jenouvrier et al. 2009, Barbraud et al. 2011). In the case of toxic chemicals, organic and metallic pollutants constitute another major threat for wildlife. However, their toxic effects have been mainly assessed at the individual and the cellular levels, under laboratory conditions. Translating these individual-level effects to population-level processes is an ultimate goal in ecotoxicology and conservation biology (e.g. Forbes and Calow 2002, Tanaka 2003). However, this populationlevel approach has been poorly applied in free-living species and some toxic effects have been estimated from controlled laboratory conditions and using closely-related species (Nakamaru et al. 2003, Miller and Ankley 2004, Willson et al. 2012).

Mercury (Hg), a heavy metal of both natural and anthropogenic releases, is a globally distributed contaminant of particular concern for aquatic biota (Wolfe et al. 1998, Scheuhammer et al. 2009). Toxic effects of $\mathrm{Hg}$ have been extensively studied in vertebrates and may include developmental, neurological, immune, behavioural and physiological impairments (Wolfe et al. 1998, Heath and Frederick 2005, Tan et al. 2009, Frederick and Jayasena 2010). Hence, one may predict strong fitness consequences in terms of mortality and lifetime reproductive success. Furthermore, the expected increase of anthropogenic $\mathrm{Hg}$ emissions in the next decades (Streets et al. 2009) raises serious environmental concerns, including population declines and extinction risks. 
In that context, previous studies have investigated the effect of $\mathrm{Hg}$ levels on survival rate: There is no evidence of Hg-induced effects on return rate in adult great skuas Catharacta skua (Thompson et al. 1991), or on apparent adult survival rates of common loons Gavia immer (Mitro et al. 2008), king eiders Somateria spectabilis and white-winged scoter Melanitta fusca (Wayland et al. 2008), using capture-mark-recapture (CMR) studies. Only a $1 \%$ difference in adult survival rates was detected in tree swallows Tachycineta bicolor between Hg-contaminated and reference sites (Hallinger et al. 2011). Regarding reproductive performances, the most $\mathrm{Hg}$ contaminated individuals were less prone to breed successfully during the current reproductive attempt (Brasso and Cristol 2008, Burgess and Meyer 2008, Jackson et al. 2011, Frederick and Jayasena 2010). Moreover, individuals that skipped the immediate breeding attempt had the highest Hg levels during the pre-breeding period (Tartu et al. 2013). Long-term data sets and recent and robust methodological approaches may be useful to estimate the effects of $\mathrm{Hg}$ on multiple life history traits, including survival rate, breeding probability, and breeding success the following year.

The present study focuses on two Antarctic top predators: the south polar skua, Catharacta maccormicki and the brown skua C. lonnbergi breeding in Antarctica and on subantarctic islands, respectively. These two Catharacta skua species are closely related, with frequent cases of hybridization (Ritz et al. 2008). Hence, we expected that $\mathrm{Hg}$ effects on demographic parameters and on population dynamics did not significantly differ between the two skua species. Top predators are expected to be the most contaminated among the organisms of the food webs, because of $\mathrm{Hg}$ biomagnification with increasing trophic level (Bargagli et al. 1998). In the Southern Ocean, Hg may reach some of the highest concentrations so far observed in surface waters of open oceans (Cossa et al. 2011). However, $\mathrm{Hg}$ levels have been poorly 
described in southern hemisphere seabird populations (Bocher et al. 2003, Blévin et al. 2013) and historical increases have been slower than in northern hemisphere seabirds (Thompson et al. 1993). The first aim of this study is to detect whether demographic traits (survival, breeding decision, probability of successfully raising at least one chick and probability of successfully raising two chicks the following year) are affected by $\mathrm{Hg}$ levels in both species, using long-term (about 10 years) data sets, individual $\mathrm{Hg}$ blood concentrations and Multi-State Mark Recapture (MSMR) models (Lebreton and Pradel 2002). The second aim of this study is to assess population-level responses to an increase of $\mathrm{Hg}$ levels. This was done by establishing a life cycle for the two skua species, by constructing corresponding matrix population models (Caswell 2001) and by including $\mathrm{Hg}$-dependent and $\mathrm{Hg}$-independent demographic traits in the models.

\section{METHODS}

\section{Study species and sites}

The study was carried out on two sites of the French Southern Territories. The south polar skua was studied on the Pointe Géologie Archipelago, Adélie Land, Antarctica (6640’S, $140^{\circ} 01^{\prime} \mathrm{E}$ ), where ca. 50 breeding pairs were monitored annually since 1964/1965 (named the 1964 breeding season). This annual breeder forages on fish and Adélie penguin (Pygoscelis adeliae) eggs and chicks during the breeding season from October to early April (Le Morvan et al. 1967). The brown skua was studied in Mayes Island ( $\left.48^{\circ} 28^{\prime} \mathrm{S}, 69^{\circ} 57^{\prime} \mathrm{E}\right)$, a subantarctic island of $2.3 \mathrm{~km}^{2}$ within the Morbihan gulf of the Kerguelen archipelago, where ca. 50 breeding pairs were monitored annually since the 1990 breeding season. This annual breeder feeds on small burrowing petrels during the breeding season from October to March (Mougeot et al. 1998). 
Both species are loosely colonial and highly territorial and lay two eggs (Furness 1996). Site tenacity and mate fidelity are high (Ainley et al. 1990, Pietz and Parmelee, 1993).

Monitoring procedures for banding and resighting were similar for the two species: all individuals were ringed with a stainless steel band and a plastic band engraved with unique alphanumeric code. This allowed individual identification at a distance with binoculars. Every year each partner of breeding pairs was identified at the time of the visits (four to eight) to the nests and territories during egg laying, incubation and chick-rearing (from early November to early February). Groups of non-breeding individuals occurring at both sites were also checked regularly for individual identification of ringed birds. Breeding performances were determined by checking the nest sites for the presence of eggs or young chicks, and nest surroundings for the presence of chicks. Chicks were ringed just before fledging. New individuals (breeders and nonbreeders) found in the territories and their surroundings were ringed each year.

\section{Blood sampling}

Skuas were captured using a nylon snare on the end of a fishing rod or using remote controlled noose traps. South polar skuas $(\mathrm{N}=76)$ were captured from the $5^{\text {th }}$ of January to the $7^{\text {th }}$ of February 2003 (32 males and 27 females) and from the $17^{\text {th }}$ of December 2004 to the $19^{\text {th }}$ of January 2005 (7 males and 10 females). In total, 13 were non-breeders, 8 were incubating and 55 were brooding. Brown skuas (31 males and 37 females) were handled from the $17^{\text {th }}$ of November to the $9^{\text {th }}$ of December 2001. Among them, 11 were non-breeders, 33 were incubating and 24 were brooding. Among non-breeders, 4 were not ringed and were thus not included in the CMR analyses. 
Blood samples $(1 \mathrm{~mL})$ were taken immediately after capture from the alar vein with a heparinized 5-mL syringe and a 25-gauge needle. After centrifugation, plasma and blood cells were separated and stored at $-20^{\circ} \mathrm{C}$ until assayed. In great skuas, blood is a good indicator of mercury intake during the breeding season (Bearhop et al. 2000).

\section{Analysis of $\mathrm{Hg}$ concentrations and molecular sexing}

Total $\mathrm{Hg}$ was measured at the laboratory Littoral ENvironnement et Sociétés (LIENSs) from lyophilized red blood cells in an Advanced Mercury Analyzer spectrophotometer (Altec AMA 254). At least two aliquots ranging from 5 to $10 \mathrm{mg}$ dry weight were analyzed for each individual and measurement quality was certified by reference material, as described by Bustamante et al. (2006). Molecular sexing was determined at the Centre d'Etudes Biologiques de Chizé (CEBC), by polymerase chain reaction (PCR) amplification of part of two highly conserved genes (CHD) present on the sex chromosomes, as detailed in Weimerskirch, Lallemand and Martin (2005).

We used R software (R Development Core Team 2012) and generalized linear models (GLMs) with quasipoisson error distribution and a log link function to test whether $\mathrm{Hg}$ levels were linked to current breeding status (non-breeding, incubating, brooding), sex, and the interaction effect between breeding status and sex.

\section{Estimating the effect of $\mathrm{Hg}$ on demographic parameters}

We evaluated the effects of $\mathrm{Hg}$ concentrations on the demographic parameters through the capture-recapture data of sampled individuals from 2002 to 2011 for the south polar skua, and from 2001 to 2011 for the brown skua. We constructed a MSMR model common to both 
species. This model distinguished five states: non-breeder (NB, defined as an individual that was not observed with an egg), failed breeder (FB, defined as an individual that was observed with one or two eggs, or one or two chicks but that failed to fledged a chick), successful breeder with one chick (SB1, defined as an individual that fledged one chick), successful breeder with two chicks (SB2, defined as an individual that fledged two chicks), and dead. The state dead (†) was an absorbing state representing death or permanent emigration from the study areas. Models were parameterized in terms of the probability of survival $(s)$, the probability of breeding $(\beta)$, the probability of breeding successfully $(\gamma)$, the probability of successfully raising two chicks $(\delta)$, and the detection probability $(p)$. Transition probabilities between states were thus modeled with a four-step procedure where $s, \beta, \gamma$ and $\delta$ were considered as four successive steps in transition matrices. Figure 1 presents a multinomial tree diagram describing the probability structure for multistate observations, and parameters of the model are defined in Table 1. We chose a MSMR approach since this allows taking into account the probability of detecting individuals given their return to the study sites. It also allows taking into account the previous breeding state of individuals which might be important to obtain unbiased estimates of demographic parameters (Lebreton and Pradel 2002).

Several constraints were made to ensure that the parameters of the model were estimable. The state dead being explicitly included in the model but being never encountered, transition probabilities from the state dead were fixed to 0 and capture probability was fixed to 0 (Pradel 2005, Choquet et al. 2009a). Because our capture-recapture analyses relied on a limited number of individual capture histories (south polar skua: $\mathrm{n}=76$, brown skua: $\mathrm{n}=64$ ) parameters $s, \beta, \gamma$ and $\delta$ were constrained to be constant over time but state dependent. With this constraint the initial model was full-rank. Detection probability was time and state dependent to allow taking 
into account variations in detectability. Note that we ran a model where all demographic parameters were time and state dependent but this model was highly rank deficient.

This MSMR model was parameterized by the survival-transition probabilities matrix:

\begin{tabular}{|c|c|c|c|c|}
\hline & NB & FB & SB1 & SB2 \\
\hline & {$[s(1-\beta)$} & $s \beta(1-\gamma)$ & $s \beta \gamma(1-\delta)$ & $\mathrm{s} \beta \gamma \delta$ \\
\hline & $s(1-\beta)$ & $s \beta(1-\gamma)$ & $s \beta \gamma(1-\delta)$ & $\mathrm{s} \beta \gamma \delta$ \\
\hline B1 & $s(1-\beta)$ & $s \beta(1-\gamma)$ & $s \beta \gamma(1-\delta)$ & $\mathrm{s} \beta \gamma \delta$ \\
\hline & $s(1-\beta)$ & $s \beta(1-\gamma)$ & $s \beta \gamma(1-\delta)$ & $\mathrm{s} \beta \gamma \delta$ \\
\hline & - & - & & \\
\hline
\end{tabular}

Because we were interested to test for sex-specific effects of $\mathrm{Hg}$ on demographic parameters we started from an initial model including an effect of sex $(g)$ on each parameter. Model selection was first performed on detection probability by testing state-dependency (difference between all states, between breeders and non-breeders, or no difference) and timedependency. We then tested for state-dependency (difference between all states, difference between breeders and non-breeders or no difference) for $s, \beta, \gamma$ and $\delta$. Once we identified the best model structure for all parameters, we tested for an effect of breeding experience (number of previous breeding attempts) for south polar skuas on demographic parameters $(s, \beta, \gamma$, or $\delta)$. Breeding experience was not available for brown skuas. Then we tested for a linear or a quadratic effect of $\mathrm{Hg}$ on demographic parameters the following year to test the hypothesis that contamination levels in one breeding season may influence the survival and breeding success of an individual in the following season. We did not test for an effect of $\mathrm{Hg}$ on current breeding success, since capture and blood sampling were mainly conducted during the chick-rearing period. We built MSMR models where each demographic parameter $\theta$ was modeled as a function of $\mathrm{Hg}$ using a logit link function: $\operatorname{logit}(\theta)=a+b \times H g_{i}$, where $a$ is an intercept, $b$ is a slope and $\mathrm{Hg}_{i}$ is $\mathrm{Hg}$ concentration for individual $i$. When $b<0$, or $b>0$, the covariate $\mathrm{Hg}$ has a 
negative or positive effect on the demographic parameter, respectively. Individual covariates, breeding experience and $\mathrm{Hg}$ were standardized. We tested the goodness-of-fit (GOF) of the timedependent MSMR model using U-CARE (Choquet et al. 2009b).

Model selection was based on Akaike's Information Criterion corrected for small sample size (AICc) (Burnham and Anderson 2002) and all models were run under program E-SURGE 1.8.5 allowing splitting transition probabilities between states (Choquet et al. 2009a).

\section{Modeling population dynamics}

To evaluate the population-level effects of $\mathrm{Hg}$ we constructed population models using pre-breeding matrices (Caswell 2001) structured by age and reproductive status classes. For south polar skuas, we built a female only age- and stage-classified matrix population model, since $\mathrm{Hg}$ similarly affected the same demographic parameters of both sexes (see Results). Based on results from a detailed demographic study on south polar skuas (Ainley et al. 1990) the model consists of four immature age classes (first year $\mathbf{J}_{1}$, second year $\mathbf{J}_{2}$, third year $\mathbf{J}_{3}$, fourth year $\mathbf{J}_{4}$ ), five pre-breeder classes (from $\mathrm{PB}_{5}$ to $\mathrm{PB}_{9}$ : individuals are able to start breeding and are thus considered as pre-breeders), and two stage-classes: breeder (B) and non-breeder (NB). Parameters entering the model were adult survival rate of breeders and non-breeders $\left(\mathrm{S}_{\mathrm{AB}}\right.$ and $\left.\mathrm{S}_{\mathrm{ANB}}\right)$, survival during the second and the third year $\left(\mathrm{S}_{1}\right.$ and $\left.\mathrm{S}_{2}\right)$, the proportion of juveniles attempting to breed $\left(\mathrm{pb}_{5}\right.$ to $\left.\mathrm{pb}_{9}\right)$, breeding probability of breeders and non-breeders $\left(\beta_{\mathrm{B}}\right.$ and $\left.\beta_{\mathrm{NB}}\right)$, fecundity, and the proportion of immigrants $(\mathrm{m})$. Fecundity was calculated as the product of clutch size (2), breeding success probability $(\gamma)$, the probability of successfully raising two chicks $(\delta)$, the survival probability during the first year at sea $\left(\mathrm{S}_{0}\right)$, and assuming a 1:1 sex ratio. 
For the brown skua, we built a two-sex age- and stage-classified matrix population model (Caswell 2001), since Hg concentrations affected the demographic parameters of males only (see Results). We used the same life cycle as the one used for south polar skuas, because brown skuas and south polar skuas are similar in size and other life history traits (Furness 1996). Moreover, to the best of our knowledge there is no detailed demographic study on brown skuas. The two-sex model was thus parameterized with the same parameters as for the south polar skua, except the fecundity which included the harmonic fertility function $n_{(f, m)} /\left(n_{f}+n_{m}\right)$, where $n_{f}$ and $n_{m}$ are the number of breeding females and males, respectively.

We first built deterministic matrix models with no stochasticity, which included the mean values of the demographic rates. Mean estimates of the demographic parameters used in the deterministic model were obtained from (Ainley et al. 1990) $\left(\mathrm{S}_{0}, \mathrm{~S}_{1}, \mathrm{~S}_{2}, \mathrm{pb}\right.$ to $\mathrm{pb}$, and $\mathrm{m}$ ) and from our MSMR model results $\left(\mathrm{S}_{\mathrm{AB}}, \mathrm{S}_{\mathrm{ANB}}, \beta_{\mathrm{B}}, \beta_{\mathrm{NB}}, \gamma\right.$ and $\left.\delta\right)$. From these matrix analyses we estimated the deterministic growth rate $(\lambda)$ and the sensitivities of $\lambda$ to variations in demographic rates $\theta(\partial \lambda / \partial \theta)$ (Caswell 2001). We then focused on stochastic matrix models to estimate the stochastic growth rate $\lambda_{\text {stoch }}$ Environmental stochasticity was included in two different ways. When a vital rate had no significant relationship with $\mathrm{Hg}$ levels, its yearly values were sampled from a beta distribution (Morris and Doak 2002), with mean and variance equal to those estimated from the MSMR model selected or taken from Ainley et al. (1990). When a vital rate had a significant relationship with $\mathrm{Hg}$ levels, its value at year $\mathrm{t}\left(\theta^{t}\right)$ was modeled as $\theta^{\mathrm{t}}=\operatorname{logit}^{-1}\left(a+b \times H g^{t}\right)$ where $\mathrm{Hg}^{\mathrm{t}}$ represents the mean $\mathrm{Hg}$ value. $\mathrm{Hg}$ values were sampled from a lognormal distribution for all individuals sampled. To assess the population-level effects of $\mathrm{Hg}$ concentrations, we estimated stochastic population growth rates according to changes in mean $\mathrm{Hg}$ levels within the range of observed $\mathrm{Hg}$ values. 
We assessed the fit of our deterministic and stochastic population models by comparing the observed annual population growth rate $\left(\lambda_{\text {obs }}\right)$ calculated as $\left(N_{t} / N_{0}\right)^{(1 / t)}($ Caughley 1977) based on the counts of the number of breeding pairs. The matrix population models were analyzed by Monte Carlo simulations (10 000 iterations) using package popbio (Stubben and Milligan 2007) implemented in program R (R Development Core Team 2012).

\section{RESULTS}

\section{Effects of sex, current breeding status, breeding experience and body conditions on $\mathrm{Hg}$ levels}

Hg levels were around 4 times higher in brown skuas (mean \pm SE: $8.22 \pm 0.24 \mu \mathrm{g} . \mathrm{g}^{-1} \mathrm{dw}$ ) than in south polar skuas $\left(2.15 \pm 0.17 \mu \mathrm{g} . \mathrm{g}^{-1} \mathrm{dw}, \mathrm{F}_{1,140}=381.07, \mathrm{p}<0.001\right)$, even when considering only breeders $\left(\mathrm{F}_{1,116}=1162.00, \mathrm{p}<0.001\right)$. Non-breeders bore higher Hg levels than incubating and chick-rearing south polar skuas, without sex difference (Fig. 3A, Table 2). Nonbreeders had lower previous breeding experience than incubating and chick-rearing birds $\left(\mathrm{F}_{2,68}=\right.$ 4.908, $\mathrm{p}=0.010$ ) and $\mathrm{Hg}$ levels decreased with increasing breeding experience in south polar skuas (Table 2). In brown skuas, non-breeding males had lower Hg levels than incubating and chick-rearing males, whereas Hg levels did not differ among females' breeding status (Fig. 3B, Table 2).

\section{Long-term fitness consequences of $\mathrm{Hg}$ exposure}

The GOF of the MSMR model was overall not significant for south polar skuas (males: $\chi^{2}$ $=15.31, \mathrm{df}=47, \mathrm{p}=1.0$ and females: $\chi^{2}=19.85, \mathrm{df}=50, \mathrm{p}=1.0$ ) and for brown skuas (males: $\chi^{2}$ 
$=13.48, \mathrm{df}=35, \mathrm{p}=1.0$ and females: $\left.\chi^{2}=19.99, \mathrm{df}=43, \mathrm{p}=0.99\right)$. For the two skuas species, the best model according to AICc (model 9, Appendix 1) states that in year $t+1$ individuals captured as breeders in year $t$ had higher apparent survival rates, higher breeding probabilities, and higher detection probabilities than non-breeders captured in year $t$, but did not differ in breeding success probabilities (Appendix 1 and Table 3).

In south polar skuas, model 12 (Table 4A) was the best model according to AICc and suggested an effect of previous breeding experience on breeding probability. However, the parameter value (-0.05) and its wide confidence interval including 0 suggested that the effect was very weak. For the two species, $\mathrm{Hg}$ levels had no effect on apparent survival rate and breeding probability the following year (models 15 to 18 , Table $4 \mathrm{~A}, \mathrm{~B}$ ). In south polar skuas, increasing Hg levels were linked to decreasing breeding success the following year (model 19, Table 4A, Fig. 4A), but not to the probability of raising successfully two chicks the following year (models 21 and 22, Table 4A). In brown skuas, breeding success the following year was not related to $\mathrm{Hg}$ levels (models 19 and 20, Table 4B), but the probability of successfully fledging two chicks the following year decreased with increasing $\mathrm{Hg}$ levels (Models 21, 22 and 23, Table 4B). Specifically, model 23 suggested that the probability of raising successfully two chicks the

following year decreased with increasing Hg levels in male brown skuas (Fig. 4B). Model 23 had the lowest AICc and the confidence interval for the slope parameter did not contain 0 (Table 4B).

\section{Hg and population growth rate}

The deterministic population growth rate was 1.002 and 1.020 for south polar skuas and brown skuas respectively, and the respective generation times were 19.4 and 23.5 years. Sensitivity analyses suggested that changes in adult survival of breeders will have the greatest 
effect on the population growth rate for both species, followed by changes in the probability of breeding, the probability of adult survival of non-breeders, and the probability of juvenile survival in the south polar skua, and by changes in the probability of breeding, the probability of juvenile survival and the probability of breeding successfully in the brown skua. In both species, changes in the probability of breeding successfully will have a greater effect on the population growth rate than changes in the probability of fledging two chicks (ratio of elasticities 4.6 to 4.7 ).

Our stochastic population model predicted an increase in the numbers of breeding pairs of south polar skua $\left(\lambda_{\text {stoch }}=1.001\right)$ and brown skua $\left(\lambda_{\text {stoch }}=1.009\right)$, which were similar to the mean annual population growth rate observed from 2003 to $2012\left(\lambda_{\text {obs }}=1.015\right)$ for south polar skuas and from 2001 to $2011\left(\lambda_{\mathrm{obs}}=1.008\right)$ for brown skuas. Population growth rates accounting for $\mathrm{Hg}$ effects from MSMR analyses were similar to the purely stochastic growth rate regardless of $\mathrm{Hg}$ effects (south polar skua, $\lambda=1.006$; brown skua, $\lambda=1.020$ ). According to our population modeling, $\mathrm{Hg}$ negatively affects population growth rate. Demographic decline $(\lambda<1)$ was

predicted for mean $\mathrm{Hg}$ levels exceeding $2.8 \mu \mathrm{g} \cdot \mathrm{g}^{-1} \mathrm{dw}$ in the south polar skua and $12 \mu \mathrm{g} \cdot \mathrm{g}^{-1} \mathrm{dw}$ in the brown skua (Fig. 5).

\section{DISCUSSION}

Using long-term data sets and MSMR models, the present study indicates no effect of $\mathrm{Hg}$ accumulation on adult survival rate and breeding probability the following year. However, $\mathrm{Hg}$ exposure decreased the probability of successfully raising at least one or two chicks the following year in the south polar skua and the brown skua, respectively. At the population level, this study suggested a slight demographic decline in response to increasing Hg levels. 


\section{Hg levels in brown skuas and south polar skuas}

$\mathrm{Hg}$ levels found in adult brown skuas and south polar skuas were within the range of those measured in the blood of adult great skuas at northeast Atlantic colonies (from $3.49 \pm 1.83$

to $6.71 \pm 3.08 \mu \mathrm{g} \cdot \mathrm{g}^{-1} \mathrm{dw}$, Bearhop et al. 2000). South polar skuas were less contaminated than brown skuas, which could be attributed to a species-specific difference in diet and trophic level during the breeding season and/or during the wintering period. On the one hand, brown skuas breeding in Kerguelen Islands feed primarily on adult blue petrels (Halobaena caerulea, Mougeot et al. 1998), a long-lived highly piscivorous seabird (Cherel et al. 2002). On the other hand, south polar skuas breeding in Adélie Land rely on fish, as well as eggs and chicks of Adélie penguin (Pygoscelis adeliae), a krill-eating seabird (Young 1963). The two species also differed in their migration pattern and wintering areas, with south polar skuas migrating further north (Japan, CEBC unpublished data; northern Atlantic and the northern Pacific Oceans, Kopp et al. 2011) than brown skuas (Australia, CEBC unpublished data; between the Antarctic Polar Front and the northern sub-tropical Front, Phillips et al. 2007). Moreover, Hg levels decreased with previous breeding experience, and differed between breeders and non-breeders in a speciesspecific manner. This could be due to a difference in foraging ecology between breeders and non-breeders. Little is known on the foraging ecology of non-breeders. Although it is conceivable that the most contaminated individuals were not functionally able to breed (Tartu et al. 2013), this was not supported by our MSMR analysis. 


\section{Long-term fitness consequences of $\mathrm{Hg}$ exposure}

In the two skua species, adult survival rates of breeders were high and similar to those previously estimated for south polar skuas (89-96\%, Ainley et al. 1990; Pietz and Parmelee, 1993) and for great skuas (82-93\%, Ratcliffe et al. 2002). Breeding probability was low in individuals previously observed as non-breeders (37-60\%) and high in breeders (about 86\%), as previously estimated (from 72 to $100 \%$ for mature south polar skuas, Ainley et al. 1990). The probability of breeding successfully was higher in brown skuas $(83.8 \%)$ than in south polar skuas (73.5\%). The probability of successfully raising two chicks was low in the two skua species (about 28\%). Although experienced seabirds are known to breed more frequently than inexperienced ones (Desprez et al. 2011), we did not detect any strong effect of previous breeding experience on breeding parameters. This could be due to our relatively low sample size and/or to an effect of experience restricted to the first reproductive attempts (Nevoux et al. 2007).

According to life-history theory, environmental stressors should have the strongest effects on life history traits with the lowest sensitivity, e.g. traits with the lowest importance for population growth (Gaillard et al. 2000, Forbes et al. 2010). In long-lived species, adult survival rate has the highest elasticity and should be the least affected by environmental stressors, whereas breeding success has the lowest elasticity and should be the most sensitive to stressors (Gaillard et al. 2000, Gaillard and Yoccoz 2003), including toxic chemicals (Forbes et al. 2010). Our results partly supported this theoretical framework, since $\mathrm{Hg}$ burden did not jeopardize adult survival in the two skua species (which had the highest elasticity by far), thereby corroborating previous studies (Thompson et al. 1991, Mitro et al. 2008, Wayland et al. 2008, Hallinger et al. 2011). Moreover, the probability to remain a breeder the following year was not affected by $\mathrm{Hg}$ 
levels. In contrast, high $\mathrm{Hg}$ levels induced detrimental effects on the probability of fledgling successfully one or two chicks the following year. The probability of fledgling successfully at least one chick had a higher elasticity than the probability of raising two chicks. This Hg-induced breeding failure was previously demonstrated during the current breeding attempt (Brasso and Cristol 2008, Burgess and Meyer 2008, Jackson et al. 2011, Frederick and Jayasena 2010), but not the following year.

Although brown skuas exhibited much higher $\mathrm{Hg}$ levels than south polar skuas, $\mathrm{Hg}$ induced effects the following year were much stronger in the south polar skua and were only detected in male brown skuas. This study clearly highlights that closely-related species did not respond similarly to toxic chemicals under natural conditions. This species-difference could be attributed to environmental conditions, such as harsh weather, food availability, and/or the interaction with others pollutants. All these environmental fluctuations may exacerbate or attenuate the Hg-induced effects on breeding success. Testing the combined effects of multistressors on survival and lifetime breeding performances is a challenging task as it would require very large data sets.

\section{Hg and population growth rate}

Anthropogenic Hg emissions are expected to rise worldwide in the next decades (Streets et al. 2009), likely resulting in growing $\mathrm{Hg}$ accumulation in Antarctic top predators. Our population models predicted that an increase of $1 \mu \mathrm{g} . \mathrm{g}^{-1} \mathrm{dw}$ in mean $\mathrm{Hg}$ levels would slightly decelerate the population growth rate of $1.51 \%$ in the south polar skua and $0.46 \%$ in the brown skua. An $\mathrm{Hg}$ increase of $0.6 \mu \mathrm{g} . \mathrm{g}^{-1} \mathrm{dw}$ in the south polar skua and of $3.8 \mu \mathrm{g} . \mathrm{g}^{-1} \mathrm{dw}$ in the brown skua would be enough to cause population declines. Hence the south polar skua from Adélie 
Land appears to be more exposed to population decline in response to $\mathrm{Hg}$ contamination than the brown skua from Kerguelen Island. These predictions could undoubtedly be worsened by other environmental perturbations. For instance, climate change is known to affect $\mathrm{Hg}$ distribution and exposure in polar ecosystems (Stern et al. 2012) and to trigger steep population declines in seabirds (Frederiksen et al. 2004, Jenouvrier et al. 2009, Barbraud et al. 2011). An additional harmful factor is the high levels of persistent organic pollutants (POPs: PCBs, pesticides) found in South Polar skuas (Bustnes et al. 2007). In glaucous gulls Larus hyperboreus, the local survival rate was negatively affect by organochlorines and was only apparent among individuals with the highest levels of contamination (Erikstad et al. 2013). Hence we urge future population modeling to take into account the coupled effects of climate change and anthropogenic pollutions (heavy metal and POPs) to predict population-levels responses to a wider range of environmental perturbations.

Translating individual-level effects of toxic chemicals to population-level processes is a crucial and ultimate goal of modern ecological research. By using recent and robust methodological approaches and long-term data sets, we showed a negative effect of $\mathrm{Hg}$ on breeding success the following year in free-living top predators. An increase of $\mathrm{Hg}$ levels may result in a slight demographic decline, as highlighted by matrix population models.

\section{Acknowledgments}

This project was supported by the French Polar Institute (IPEV, program 109, H. Weimerskirch), Agence Nationale de la Recherche (ANR PolarTop, O. Chastel), Terres Australes et Antarctiques Françaises, Zone Atelier de Recherches sur l'Environnement 
Antarctique et Subantarctique (CNRS-INEE). Field procedures and blood sampling were authorized by the Ethics Committee of IPEV and by the Comite de l'Environnement Polaire. The

authors thank G. Bouteloup, R. Bernard, F. Angelier, B. Moe and all the wintering fieldworkers involved in the long-term monitoring programs for their help on the field, and D. Besson for managing the long-term data base.

\section{References}

Ainley, D. G., C. A. Ribic, and R. C. Wood. 1990. A demographic study of the South Polar Skua Catharacta maccormicki at Cape Crozier. Journal of Animal Ecology 59:1-20.

Barbraud, C., P. Rivalan, P. Inchausti, M. Nevoux, V. Rolland, and H. Weimerskirch. 2011. Contrasted demographic responses facing future climate change in Southern Ocean seabirds. Journal of Animal Ecology 80:89-100.

Bargagli R, F. Monaci, J. C. Sanchez-Hernandez, and D. Cateni. 1998. Biomagnification of mercury in an Antarctic marine coastal food web. Marine Ecology Progress Series 169:65-76.

Bearhop, S., R. A. Phillips, D. R. Thompson, S. Waldron, and R. W. Furness. 2000. Variability in mercury concentrations of great skuas Catharacta skua: the influence of colony, diet and trophic status inferred from stable isotope signatures. Marine Ecology Progress Series 195:261268.

Blévin, P., A. Carravieri, A. Jaeger, O. Chastel, P. Bustamante, and Y. Cherel. 2013. Wide Range of Mercury Contamination in Chicks of Southern Ocean Seabirds. PLoS ONE 8(1): e54508. 
Bocher, P., F. Caurant, P. Miramand, Y. Cherel, and P. Bustamante. 2003. Influence of the diet on the bioaccumulation of heavy metals in zooplankton-eating petrels at Kerguelen archipelago, Southern Indian Ocean. Polar Biology 26: 759-767.

Brasso, R. L. and D. A. Cristol. 2008. Effects of mercury exposure on reproductive success of tree swallows (Tachycineta bicolor). Ecotoxicology 17:133-141.

Burgess, N. M. and M. W. Meyer. 2008. Methylmercury exposure associated with reduced productivity in common loons. Ecotoxicology 17:83-91.

Burnham, K. P. and D. R. Anderson. 2002. Model selection and multimodel inference: a practical information-theoretic approach. Springer, New York.

Bustamante, P., V. Lahaye, C. Durnez, C. Churlaud, F. Caurant. 2006. Total and organic Hg concentrations in cephalopods from the North East Atlantic waters: influence of geographical origin and feeding ecology. Science of the Total Environment 368:585-596.

Bustnes, J. O., Tveraa, T., Varpe, Ø., Henden, J. A., Skaare, J. U. 2007. Reproductive performance and organochlorine pollutants in an Antarctic marine top predator: the south polar skua. Environment International 33:911-918.

Caswell, H. 2001. Matrix population models: constructions, analysis and interpretation, 2nd edn. Sinauer Associates, Sunderland, MA, USA.

Caughley, G. 1977. Analysis of Vertebrate Populations. John Wiley \& Sons, New York, NY, USA. 
Cherel, Y., Bocher, P., Trouvé, C. and Weimerskirch, H. 2002. Diet and feeding ecology of blue petrels Halobaena caerulea at Iles Kerguelen, Southern Indian Ocean. Marine Ecology Progress Series 228,283-299.

Choquet, R., L. Rouan, and R. Pradel. 2009a. Program E-SURGE: a software application for fitting multievent models. In: Thomson DL, Cooch EG, Conroy MJ (eds) Modeling demographic processes in marked populations. Springer, New York, pp 845-865.

Choquet, R., J. D. Lebreton, O. Gimenez, A. M. Reboulet, and R. Pradel. 2009b. U-CARE: Utilities for performing goodness of fit tests and manipulating CApture-REcapture data. Ecography 32:1071-1074.

Cossa, D., L. E. Heimburger, D. Lannuzel, S. R. Rintoul, C. V. Butler, A. R. Bowie, B. Averty, R. J. Watson, T. Remenyi. 2011. Mercury in the Southern Ocean. Geochimica Cosmochimica Acta 75:4037-52.

Desprez, M., R. Pradel, E. Cam, J. Y Monnat, and O. Gimenez. 2011. Now you see him, now you don't: experience, not age, is related to reproduction in kittiwakes. Proceedings of the Royal Society B 278:3060-3066.

Erikstad, K. E., H. Sandvik, T. K. Reiertsen, J. O. Bustnes, H. Strøm. 2013. Persistent organic pollution in a high-Arctic top predator: sex-dependent thresholds in adult survival. Proceedings of the Royal Society B 280: 20131483.

Frederick, P. and N. Jayasena. 2010. Altered pairing behaviour and reproductive success in white ibises exposed to environmentally relevant concentrations of methylmercury. Proceedings of the Royal Society B 278:1851-1857. 
Frederiksen, M., S. Wanless, M. P. Harris, P. Rothery, and L. J. Wilson. 2004. The role of industrial fisheries and oceanographic change in the decline of North Sea black-legged kittiwakes. Journal of Applied Ecology 41:1129-1139.

Forbes, V. E., and P. Calow. 2002. Population growth rate as a basis for ecological risk assessment of toxic chemicals. Ecological risk assessment and populations growth rate. The Royal Society. 1299-1306.

Forbes, V. E., M. Olsen, A. Palmqvist, and P. Calow, 2010. Environmentally sensitive life-cycle traits have low elasticity: implications for theory and practice. Ecological Applications 20: 14491455.

Furness, R. W. 1996. Family Stercorariidae (Skuas). Pp. 556-571 in: del Hoyo, J., Elliott, A. \& Sargatal, J. eds. Handbook of the Birds of the World. Vol. 3. Hoatzin to Auks. Lynx Edicions, Barcelona.

Gaillard, J. M. and N. G. Yoccoz. 2003. Temporal variation in survival of mammals: a case of environmental canalization? Ecology 84:3294-3306.

Gaillard, J. M., M. Festa-Bianchet, N. G. Yoccoz, A. Loison, and C. Toïgo. 2000. Temporal variation in fitness components and population dynamics of large herbivores. Annual Review of Ecology and Systematics 31:367-393.

Hallinger, K. K., K. L. Cornell, R. L. Brasso, and D. A. Cristol. 2011. Mercury exposure and survival in free-living tree swallows (Tachycineta bicolor). Ecotoxicology London England 20:39-46. 
Heath, J. A. and P. C. Frederick. 2005. Relationships among mercury concentrations, hormones, and nesting effort of white ibises (Eudocimus albus) in the Florida Everglades. Auk 122:255267.

Jackson, A. J., D. C. Evers, M. A. Etterson, A. M. Condon,S. B. Folsom, J. Detweiler, J. Schmerfeld, and D. A. Cristol. 2011. Mercury exposure affects the reproductive success of a free-living terrestrial songbird, the Carolina wren (Thryothorus ludovicianus). Auk 128:759-769.

Jenouvrier, S., H. Caswell, C. Barbraud, M. Holland, J. Stroeve, and H. Weimerskirch. 2009. Demographic models and IPCC climate projections predict the decline of an emperor penguin population. Proceedings of the National Academy of Sciences of the United States of America 106:1844-1847.

Kopp, M., H.-U. Peter, O. Mustafa, S. Lisovski, M. S. Ritz, R. A. Phillips, and S. Hahn. 2011. South polar skuas from a single breeding population overwinter in different oceans though show similar migration patterns. Marine Ecology Progress Series 435:263-267.

Lebreton, J.-D., and R. Pradel. 2002. Multistate recapture models: modelling incomplete individual histories. Journal Of Applied Statistics 29:353-369.

Le Morvan, P., J. L. Mougin, and J. Prévost. 1967. Ecologie du skua antarctique (Stercorarius skua maccormicki) dans l'archipel de Pointe Géologie (Terre Adélie). L'Oiseau RFO 37:193-220.

Miller, D. H., and G. T. Ankley. 2004. Modeling impacts on populations: fathead minnow (Pimephales promelas) exposure to the endocrine disruptor 17-B trenbolone as a case study. Ecotoxicology and Environmental Safety 59:1-9. 
Mitro, M. G., D. C., Evers, M. W. Meyer, and W. H. Piper. 2008. Common loon survival rates and mercury in New England and Wisconsin. Journal of Wildlife Management72:665-673.

Morris, W. F., and D. F. Doak. 2002. Quantitative Conservation Biology: the Theory and Practice of Population Viability Analysis. Sinauer Associates. Sunderland, MA.

Mougeot, F., F. Genevois, and V. Bretagnolle. 1998. Predation on burrowing petrels by the brown skua (Catharacta skua lonnbergi) at Mayes Island, Kerguelen. Journal of Zoology (London) 244:429-438.

Nakamaru, M., Y. Iwasa, and J. Nakanishi. 2003. Extinction risk to bird populations caused by DDT exposure. Chemosphere 53:377-387.

Nevoux, M., Weimerskirch, H., and Barbraud, C. 2007. Environmental variation and experiencerelated differences in the demography of the long-lived black-browed albatross. Journal of Animal Ecology 76:159-167.

Phillips, R. A., P. Catry, J. R. D. Silk, S. Bearhop, R. McGill, V. Afanasyev, and I. J. Strange. 2007. Movements, winter distribution and activity patterns of Falkland and brown skuas: insights from loggers and isotopes. Marine Ecology Progress Series 345:281-291.

Pietz, P. J. and D. F. Parmelee. 1993. Survival, site and mate fidelity in south polar skuas Catharacta maccormicki at Anvers Island, Antarctica. Ibis 135:32-38.

Pradel R. 2005. Multievent: An extension of multistate capture-recapture models to uncertain states. Biometrics, 61:442-447.

R Core Team. 2012. R: A language and environment for statistical computing. R Foundation for Statistical Computing, Vienna, Austria. ISBN 3-900051-07-0, URL http://www.R-project.org/. 
Ratcliffe, N., Catry, P., Hamer, K. C., Klomp, N. I., and Furness, R. W. 2002. The effect of age and year on the survival of breeding adult Great Skuas Catharacta skua in Shteland. Ibis 144: 384-392.

Ritz, M. S., C. Millar, G. D. Miller, R. A. Phillips, P. Ryan, V. Sternkopf, D. Liebers-Helbig, and H-U. Peter. 2008. Phylogeography of the southern skua complex - rapid colonization of the southern hemisphere during a glacial period and reticulate evolution. Molecular Phylogenetics and Evolution 49:292-303.

Scheuhammer, A. M., M. W. Meyer, M. B. Sandheinrich, and M. W. Murray. 2009. Effects of environmental methylmercury on the health of wild birds, mammals, and fish. AMBIO J. Hum. Environ. 36:12-19.

Seber, G. A. F. 1982. The estimation of animal abundance ad related parameters. MacMillan, New York.

Stern, G. A., R. W. Macdonald, P. M. Outridge, S. Wilson, J. Chételat, A. Cole, H. Hintelmann, L. L. Loseto, A. Steffen, F. Wang, and C. Zdanowicz. 2012. How does climate change influence arctic mercury? Science of the Total Environment 414:22-42.

Streets, D. G., Q. Zhang, and Y. Wu. 2009. Projections of global mercury emissions in 2050. Environmental Science and Technology 43:2983-2988.

Stubben, C. and B. Milligan. 2007. Estimating and analyzing demographic models using the popbio package in R. Journal of Statistical Software, 22, http://www.jstatsoft.org/v22/i11/paper

Tan, S. W., J. C. Meiller, and K. R. Mahaffey. 2009. The endocrine effects of mercury in humans and wildlife. Critical Reviews in Toxicology 39:228-269. 
Tanaka, Y. 2003. Ecological risk assessment of pollutant chemicals: extinction risk based on population-level effects. Chemosphere 53:421-425.

Tartu, S., A. Goutte, P. Bustamante, F. Angelier, B. Moe, C. Clément-Chastel, C. Bech, G. W. Gabrielsen, J. O. Bustnes, and O. Chastel. 2013. To breed or not to breed: endocrine response to mercury contamination by an arctic seabird. Biology Letters 9, 20130317.

Thomas, C. D., Cameron, A., Green,R. E., Bakkenes, M., Beaumont, L. J., Collingham, Y. C. Erasmus, B. F. N. , Ferreira de Siqueira, M., Grainger, A., Hannah, L., Hughes, L., Huntley, B., van Jaarsveld, A. S., Midgley, G. F., Miles, L., Ortega-Huerta, M. A., Townsend Peterson, A., Phillips, O. L. and Williams, S. E. 2004. Extinction risk from climate change. Nature 427:145148.

Thompson, D. R., R.W. Furness, and S.A. Lewis. 1993. Temporal and spatial variation in mercury concentrations in some albatrosses and petrels from the sub-Antarctic. Polar Biology, $13: 239-244$.

Thompson, D. R, K. C. Hamer, and R. W. Furness. 1991. Mercury accumulation in great skuas Catharacta skua of known age and sex, and its effects upon breeding and survival. Journal of Applied Ecology 28:672-684.

Wayland, M., K. L. Drake, R. T. Alisauskas, D. K. Kellett, J. Traylor, C. Swoboda, and K. Mehl. 2008. Survival rates and blood metal concentrations in two species of free-ranging North American sea ducks. Environmental Toxicology and Chemistry 27:698-704.

Weimerskirch, H., J. Lallemand, and J. Martin. 2005. Population sex ratio variation in a monogamous long-lived bird, the wandering albatross. Journal of Animal Ecology 74:285-291. 
Willson, J. D., W. A. Hopkins, C. M. Bergeron, and B. D. Todd. 2012. Making leaps in amphibian ecotoxicology: translating individual-level effects of environmental contaminants to population viability. Ecological Applications 22:1791-1802.

Wolfe, M. F., S. Schwarzbach, and R. A. Sulaiman. 1998. Effects of mercury on wildlife: a comprehensive review. Environmental Toxicology and Chemistry 17:146-160.

Young, E. C. 1963. Feeding habits of the South Polar Skua Catharacta maccormicki. Ibis 105:301-318. 
Table 1. Definition of parameters used in the multistate mark-recapture model

\begin{tabular}{|l|l|}
\hline Parameter & Definition \\
\hline$s_{s}^{t}$ & Probability that an individual in state $s$ at time t survives to time $t+1$ and does not \\
permanently emigrate from the study area \\
\hline$\beta_{s}^{t}$ & $\begin{array}{l}\text { Probability that an individual in state } s \text { at time } \mathrm{t} \text { breeds at time } t+1 \text { given that it } \\
\text { survives to } t+1\end{array}$ \\
\hline$\gamma_{s}^{t}$ & $\begin{array}{l}\text { Probability that an individual in state } \mathrm{s} \text { at time t breeds successfully at time } \mathrm{t}+1 \text { given } \\
\text { that it survives to and breeds at time } \mathrm{t}+1\end{array}$ \\
\hline$\delta_{s}^{t}$ & $\begin{array}{l}\text { Probability that an individual in state } s \text { at time } t \text { raises successfully two chicks at time } t \\
+1 \text { given that it survives to and breeds successfully at time } t+1\end{array}$ \\
\hline$p_{s}^{t}$ & \begin{tabular}{l} 
Probability that an individual in state $s$ at time $\mathrm{t}$ is encountered at time $t+1$ \\
\hline
\end{tabular}
\end{tabular}


Table 2. Testing Hg levels as a function of breeding status in the year of blood sampling (nonbreeding, incubating and brooding), sex, the interaction between breeding status and sex, breeding experience prior to the year of blood sampling, using GLMs (quasipoisson error distribution and a log link function) in south polar skuas and brown skuas.

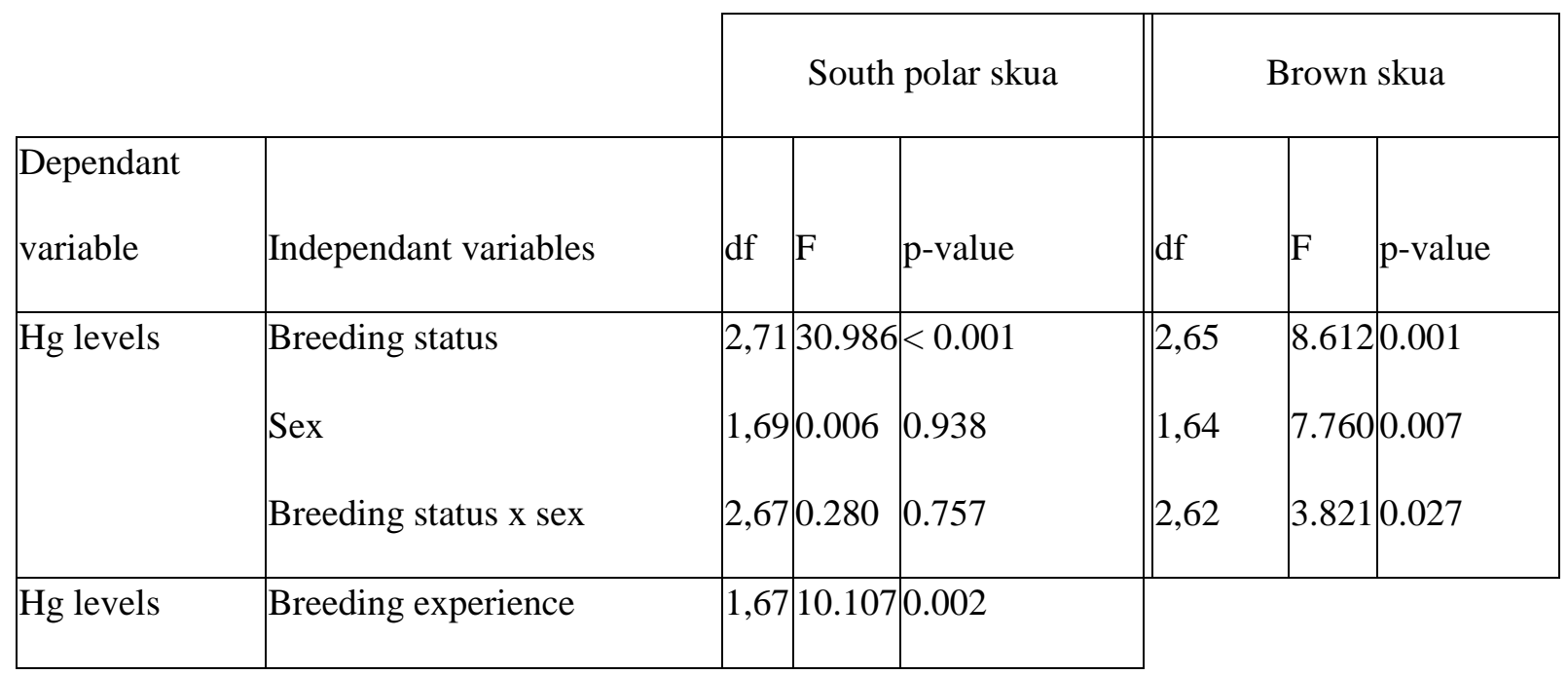


Table 3. Estimation of parameters (mean and CI) calculated from the best model (model 9) for south polar skuas and brown skuas.

\begin{tabular}{|l|cc|}
\hline South polar skuas & Non breeders & Breeders \\
\hline$s:$ apparent survival rate (\%) & $0.83[0.72-0.91]$ & $0.93[0.89-0.95]$ \\
$\beta$ : Breeding probability (\%) & $0.60[0.48-0.71]$ & $0.85[0.81-0.89]$ \\
$\gamma:$ Breeding success (\%) & $0.74[0.68-0.78]$ \\
$\delta:$ Probability of successfully brooding 2 chicks (\%) & $0.28[0.23-0.34]$ \\
$p:$ Detection probability (\%) & $0.59[0.46-0.70]$ & $1.00[1.00-1.00]$ \\
\hline
\end{tabular}

\begin{tabular}{|l|cc|}
\hline Brown skuas & Non breeders & Breeders \\
\hline$s:$ apparent survival rate (\%) & $0.80[0.66-0.89]$ & $0.95[0.90-0.97]$ \\
$\beta$ : Breeding probability (\%) & $0.37[0.25-0.50]$ & $0.87[0.82-0.90]$ \\
$\gamma:$ Breeding success $(\%)$ & $0.84[0.79-0.88]$ \\
$\delta:$ Probability of successfully brooding 2 chicks (\%) & $0.28[0.23-0.34]$ \\
$p:$ Detection probability (\%) & $0.41[0.29-0.55]$ & $1.00[1.00-1.00]$ \\
\hline
\end{tabular}


Table 4. Modeling the effects of experience, $\mathrm{Hg}$ levels and sex on demographic parameters of south polar skuas (A), and of $\mathrm{Hg}$ levels and sex on demographic parameters on brown skuas (B). The effects of standardized breeding experience were tested on each parameter. The effects of standardized Hg levels (lin: linear relationship, quad: quadratic relationship) were then tested on each parameter the following year, with or without an interaction effect between $\mathrm{Hg}$ and sex.

\section{A. South polar skuas}

\begin{tabular}{|lccccc|}
\hline Hypothesis & \# Model & Rank & Deviance & $\Delta$ AICc & Slope $[\mathrm{CI}]$ \\
\hline Effect of experience on $\beta$ & 12 & 13 & 1537.71 & 0 & $-0.05[-0.34 ; 0.24]$ \\
No effect of Hg experience on $s, \beta, \gamma$ and $\delta$ & 9 & 11 & 1543.36 & 1.42 & \\
Effect of experience on $\gamma$ & 13 & 12 & 1542.97 & 3.14 & \\
Effect of experience on $\delta$ & 14 & 12 & 1543.34 & 3.51 & \\
Effect of experience on $s$ & 11 & 13 & 1549.40 & 11.69 & \\
\hline
\end{tabular}

\begin{tabular}{|c|c|c|c|c|c|}
\hline Effect of $\mathrm{Hg}$ (lin) on $\gamma$ & 19 & 13 & 1530.89 & 0 & $-1.92[-3.40 ;-0.45]$ \\
\hline Effect of $\mathrm{Hg}$ (quad) on $\gamma$ & 27 & 14 & 15.30 .26 & 1.51 & \\
\hline \multicolumn{6}{|c|}{ Effect of $\mathrm{Hg}$ (lin) on $\gamma$ with an interaction effect } \\
\hline $\mathrm{Hg} \times \mathrm{sex}$ & 20 & 15 & 1530.39 & 3.77 & \\
\hline Effect of $\mathrm{Hg}$ (lin) on $\delta$ & 21 & 13 & 1537.81 & 6.93 & \\
\hline \multicolumn{6}{|c|}{ Effect of $\mathrm{Hg}$ (quad) on $\gamma$ with an interaction } \\
\hline effect $\mathrm{Hg}$ x sex & 28 & 17 & 1529.56 & 7.26 & \\
\hline No effect of $\mathrm{Hg}$ (lin) on $s, \beta, \gamma$ and $\delta$ & 9 & 11 & 1543.36 & 8.24 & \\
\hline Effect of $\mathrm{Hg}$ (lin) on $\delta$ & 29 & 14 & 1537.12 & 8.37 & \\
\hline \multicolumn{6}{|c|}{ Effect of $\mathrm{Hg}$ (lin) on $s$ with an interaction effect } \\
\hline Hg x sex & 16 & 18 & 1528.70 & 8.57 & \\
\hline \multicolumn{6}{|c|}{ Effect of $\mathrm{Hg}$ (lin) on $\delta$ with an interaction effect } \\
\hline Hg x sex & 22 & 15 & 1536.32 & 9.70 & \\
\hline
\end{tabular}


Effect of $\mathrm{Hg}$ (quad) on $\delta$ with an interaction

effect $\mathrm{Hg}$ x sex

$\begin{array}{llll}30 & 17 & 1532.10 \quad 9.80\end{array}$

Effect of $\mathrm{Hg}$ (quad) on $\beta$

$\begin{array}{llll}25 & 17 & 1532.33 & 10.03\end{array}$

Effect of $\mathrm{Hg}$ (quad) on $\beta$ with an interaction

effect Hg x sex

$\begin{array}{llll}26 & 23 & 1521.53 & 12.42\end{array}$

Effect of $\mathrm{Hg}$ (lin) on $s$

$\begin{array}{llll}15 & 14 & 1541.22 & 12.47\end{array}$

Effect of $\mathrm{Hg}$ (lin) on $\beta$ with an interaction effect

Hg x sex

$\begin{array}{llll}18 & 18 & 1532.61 & 12.48\end{array}$

Effect of $\mathrm{Hg}$ (lin) on $\beta$

$\begin{array}{llll}17 & 14 & 1541.85 & 13.10\end{array}$

Effect of $\mathrm{Hg}$ (quad) on $s$ with an interaction

effect Hg x sex

$\begin{array}{llll}24 & 23 & 1524.11 & 14.99\end{array}$

Effect of $\mathrm{Hg}$ (quad) on $s$

$\begin{array}{llll}23 & 17 & 1539.27 & 16.97\end{array}$

\section{B. Brown skuas}

\begin{tabular}{|c|c|c|c|c|c|}
\hline Hypothesis & $\begin{array}{c}\# \\
\text { Model }\end{array}$ & Rank & Deviance & $\triangle \mathrm{AICc}$ & Slope $[\mathrm{CI}]$ \\
\hline Effect of $\mathrm{Hg}$ (lin) of males on $\delta$ & 23 & 14 & 1332.10 & 0 & $-1.70[-3.34 ;-0.06]$ \\
\hline Effect of $\mathrm{Hg}$ (lin) on $\delta$ & 21 & 13 & 1335.54 & 1.29 & $-0.58[-1.36 ; 0.20]$ \\
\hline Effect of $\mathrm{Hg}$ (lin) on $\delta$ with an interaction effect & 22 & 15 & 1331.74 & 1.80 & M:-1.70 [-3.33;-0.06] \\
\hline $\operatorname{Hg} \mathrm{x}$ sex & & & & & $F:-0.40[-1.72 ; 0.93]$ \\
\hline Effect of $\mathrm{Hg}$ (quad) on $\delta$ & 31 & 14 & 1335.50 & 3.40 & \\
\hline Effect of $\mathrm{Hg}$ (lin) of females on $\delta$ & 24 & 14 & 1337.40 & 5.30 & \\
\hline No effect of $\mathrm{Hg}$ (lin) on $s, \beta, \gamma$ and $\delta$ & 9 & 11 & 1344.80 & 6.29 & \\
\hline Effect of $\mathrm{Hg}$ (quad) on $s$ & 25 & 17 & 1334.28 & 8.70 & \\
\hline $\begin{array}{l}\text { Effect of } \mathrm{Hg} \text { (quad) on } \delta \text { with an interaction effect } \\
\mathrm{Hg} \times \text { sex }\end{array}$ & 32 & 17 & 1335.42 & 10.62 & \\
\hline Effect of $\mathrm{Hg}$ (quad) on $\gamma$ & 29 & 14 & 1343.00 & 10.90 & \\
\hline
\end{tabular}




\begin{tabular}{|c|c|c|c|c|}
\hline Effect of $\mathrm{Hg}$ (quad) on $\beta$ & 27 & 17 & 1337.01 & 11.42 \\
\hline Effect of $\mathrm{Hg}$ (lin) on $s$ & 15 & 15 & 1342.40 & 12.46 \\
\hline $\begin{array}{l}\text { Effect of } \mathrm{Hg} \text { (lin) on } \gamma \text { with an interaction effect } \\
\mathrm{Hg} \mathrm{x} \text { sex }\end{array}$ & 20 & 15 & 1343.69 & 13.75 \\
\hline $\begin{array}{l}\text { Effect of } \mathrm{Hg} \text { (quad) on } \gamma \text { with an interaction effect } \\
\mathrm{Hg} \mathrm{x} \text { sex }\end{array}$ & 30 & 17 & 1340.57 & 14.98 \\
\hline $\begin{array}{l}\text { Effect of } \mathrm{Hg} \text { (lin) on } \beta \text { with an interaction effect } \\
\mathrm{Hg} \mathrm{x} \text { sex }\end{array}$ & 18 & 19 & 1337.53 & 16.34 \\
\hline $\begin{array}{l}\text { Effect of } \mathrm{Hg} \text { (lin) on } s \text { with an interaction effect } \\
\mathrm{Hg} \mathrm{x} \text { sex }\end{array}$ & 16 & 19 & 1338.52 & 17.33 \\
\hline Effect of $\mathrm{Hg}$ (lin) on $\gamma$ & 19 & 13 & 1351.22 & 16.98 \\
\hline $\begin{array}{l}\text { Effect of } \mathrm{Hg} \text { (quad) on } s \text { with an interaction effect } \\
\mathrm{Hg} \times \text { sex }\end{array}$ & 26 & 23 & 1330.83 & 18.57 \\
\hline $\begin{array}{l}\text { Effect of } \mathrm{Hg} \text { (quad) on } \beta \text { with an interaction effect } \\
\mathrm{Hg} \times \mathrm{x} \text { sex }\end{array}$ & 28 & 23 & 1336.18 & 23.92 \\
\hline Effect of $\mathrm{Hg}$ (lin) on $\beta$ & 17 & 15 & 1479.61 & 149.67 \\
\hline
\end{tabular}




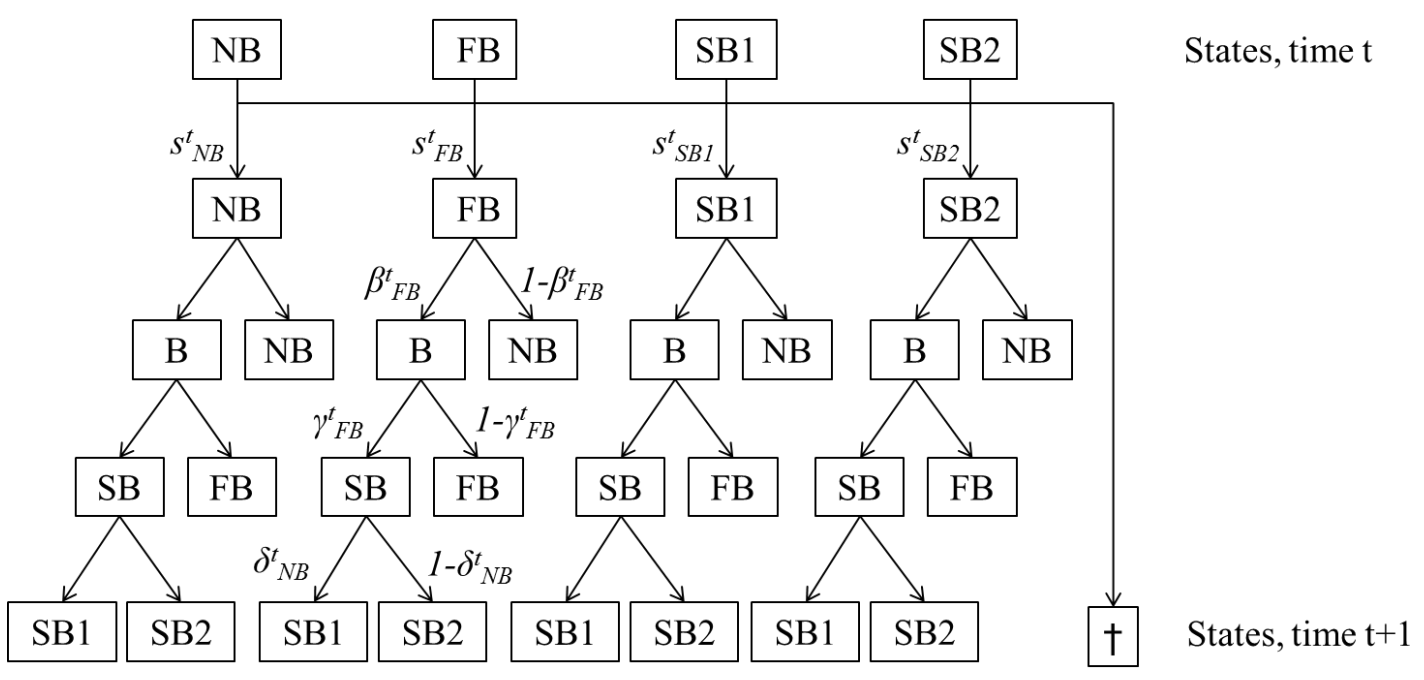

Figure 1. A multinomial tree diagram describing the probability structure for multistate observations. Solid boxes indicate the states alive in state NB (non-breeder), FB (failed breeder), SB1 (successful breeder with one chick), SB2 (successful breeder with two chicks), dead. State transition probabilities were decomposed in a four-step process. The state transitions $(\mathrm{s}, \beta, \gamma, \delta)$ are defined in Table 1 and states in the Methods section. 


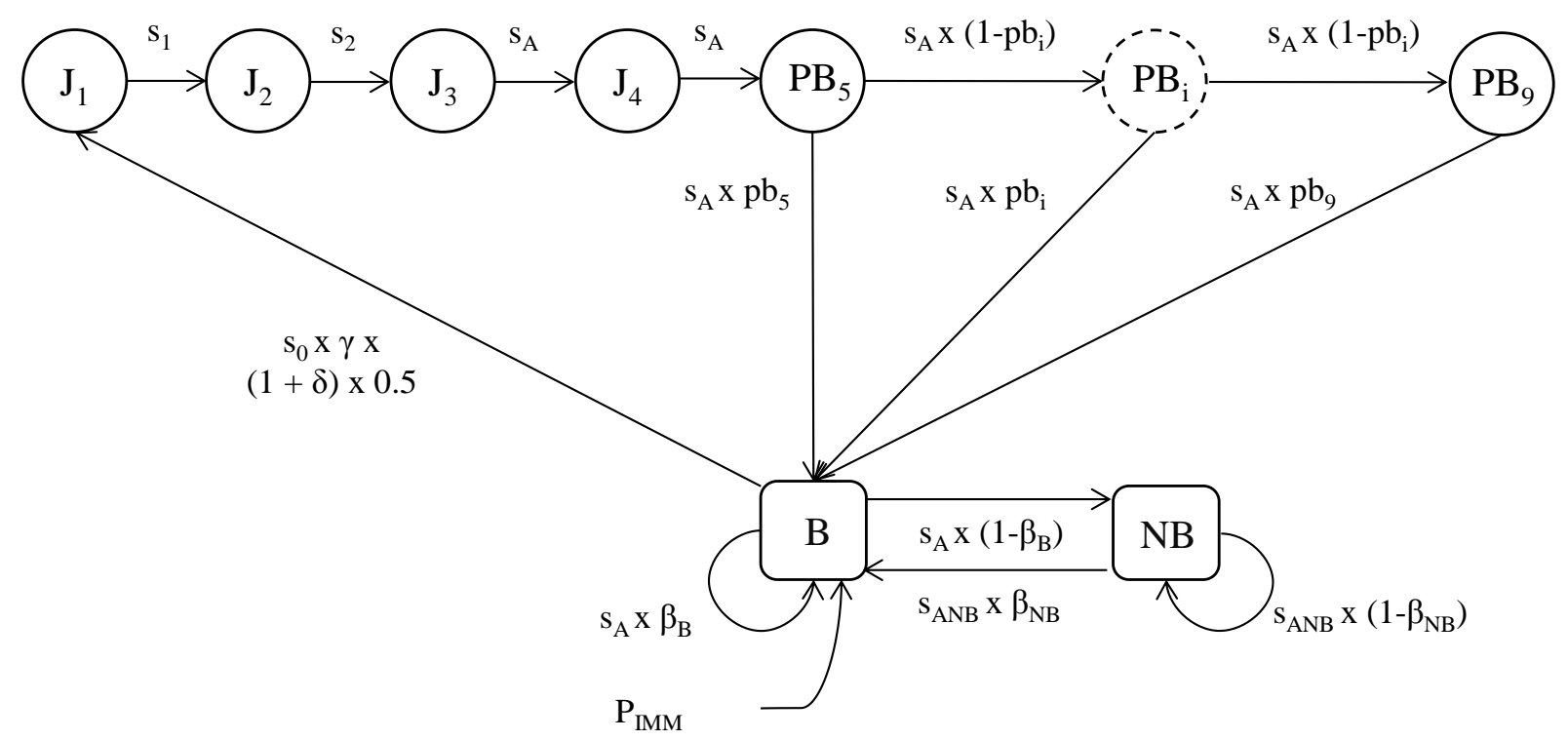

Figure 2. Lifetime cycle graph for the brown skua and the south polar skua. Ji: juvenile of age class i; PBi: pre-breeder of age class i; B: adult breeder; NB: adult non-breeder; S0: survival during the first year at sea; Si: survival probability of age class i; SA: adult breeder survival probability; SANB: adult non-breeder survival probability; pbi: proportion of pre-breeders of age class $i$ attempting to breed for the first time; $\beta$ B: breeding probability of breeders; $\beta \mathrm{NB}$ : breeding probability of non-breeders; $\gamma$ : probability of breeding successfully; $\delta$ : probability of successfully raising two chicks; PIMM: immigration rate. 

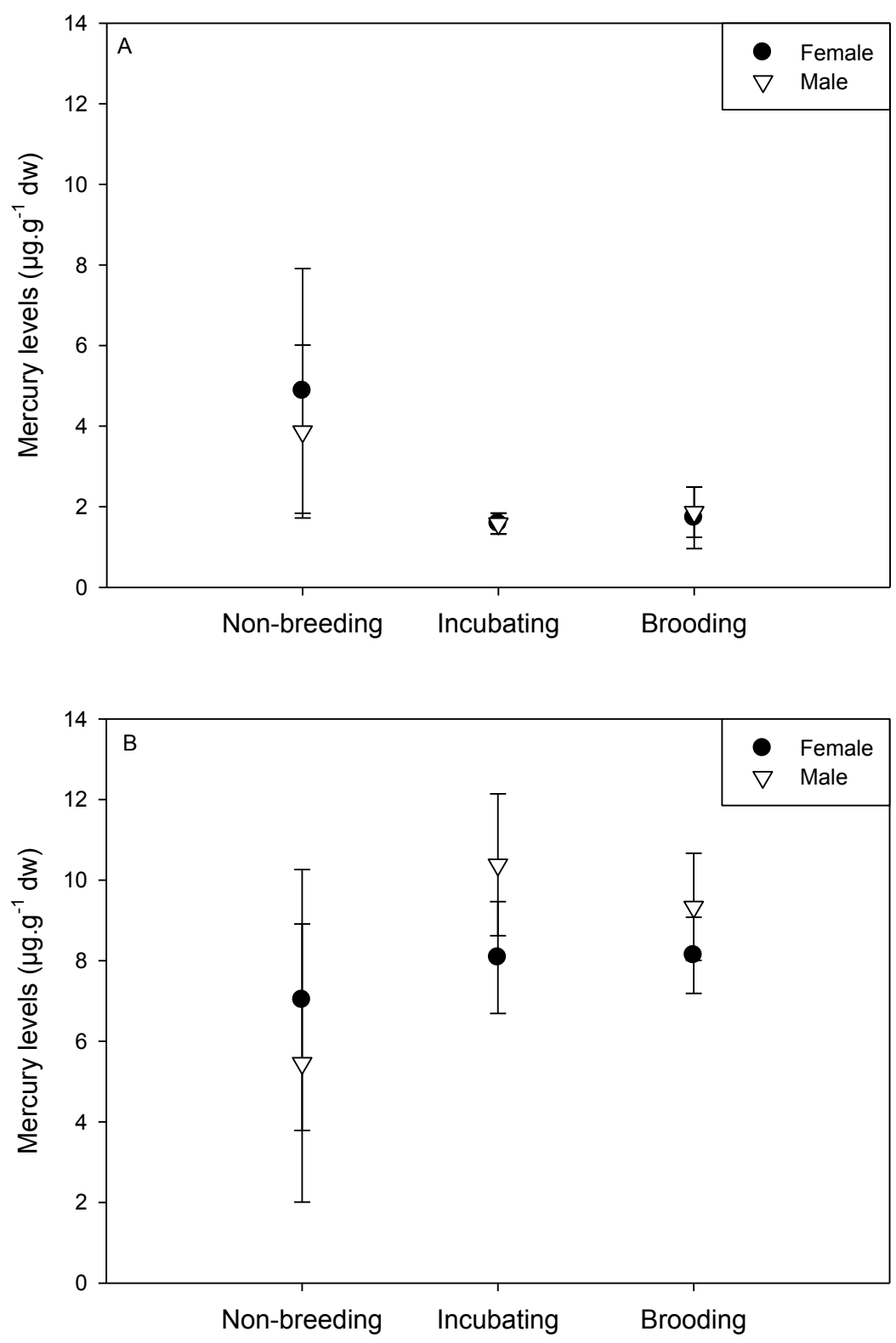

Figure 3. Hg levels (means and SD, $\mu \mathrm{g} \cdot \mathrm{g}^{-1} \mathrm{dw}$ ) in non-breeding, incubating and brooding (A) south polar skuas and (B) brown skuas. Open triangles denote males and filled circles denote females. 

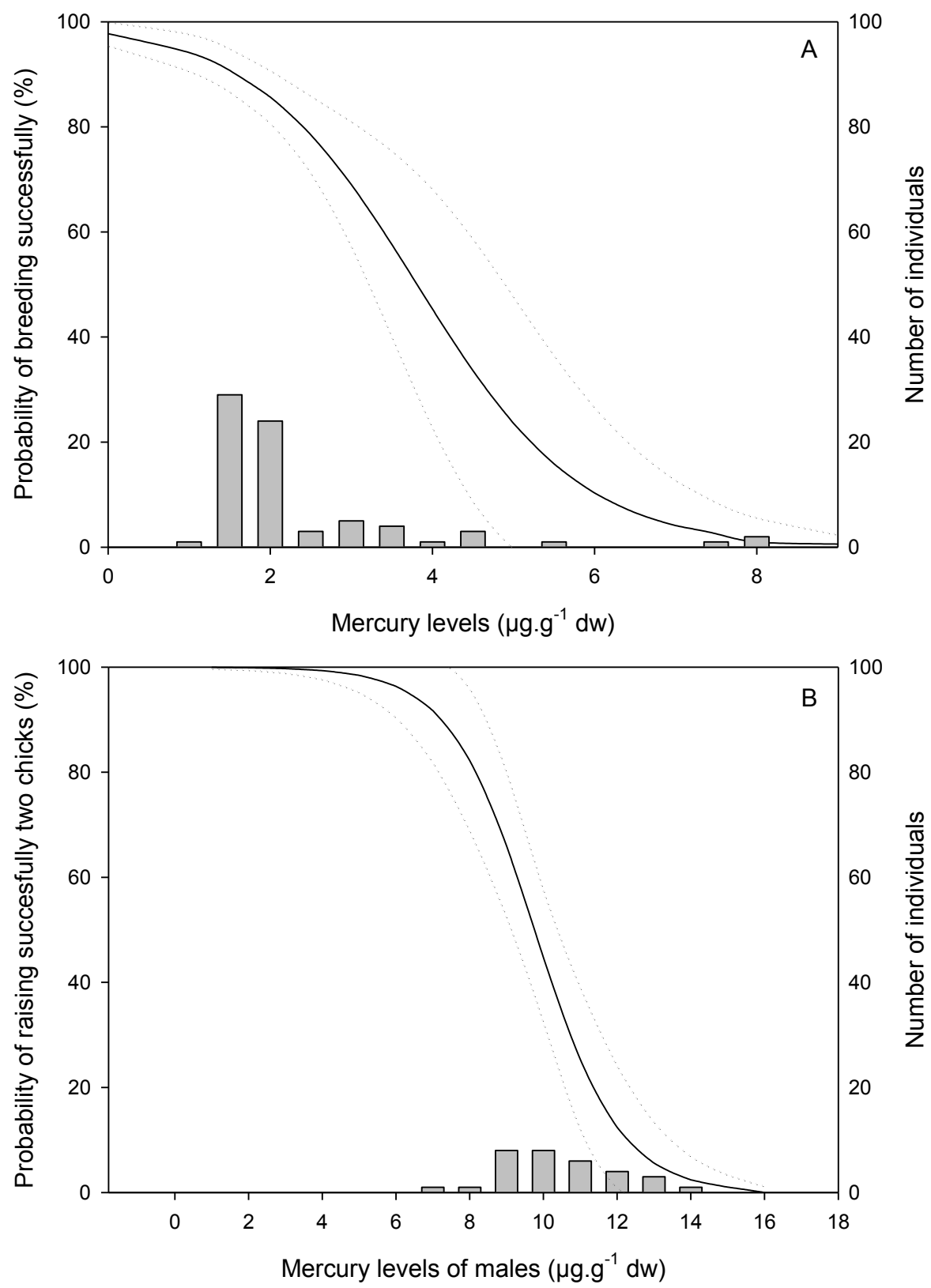

Figure 4. Effects of $\mathrm{Hg}$ on (A) the probability of breeding successfully the following year in south polar skuas (from model 19, table 4A) and (B) the probability of raising two chicks the following year in brown skuas (from model 23, table 4B). Histograms represent the measured $\mathrm{Hg}$ levels in the sampled individuals. Dotted lines represent $95 \%$ confidence intervals estimated using the delta method (Seber 1982). 


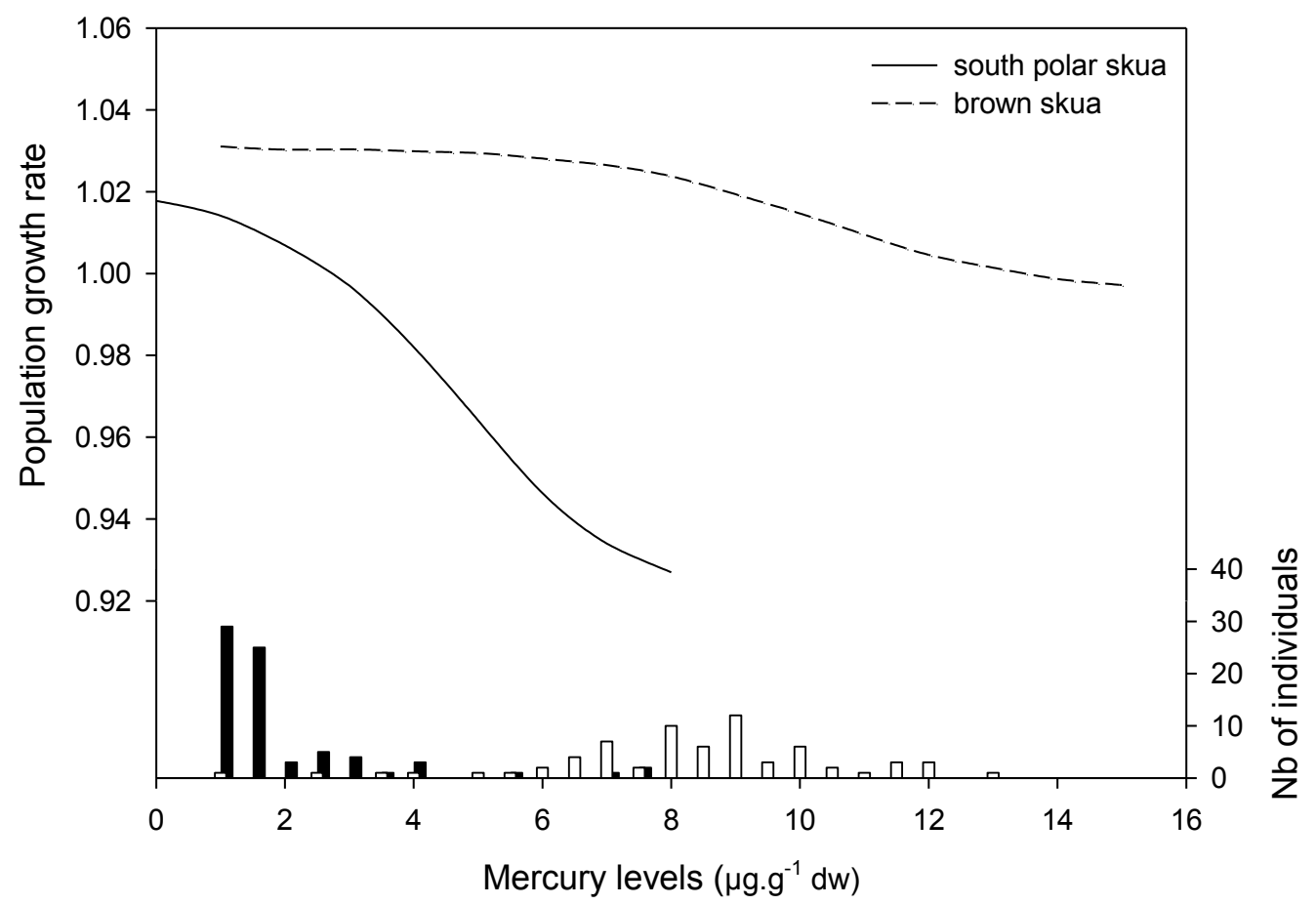

Figure 5. Modeled population level responses to an increase of mean Hg levels. Histograms of the observed range of $\mathrm{Hg}$ levels are given in black box for south polar skua and white box for brown skua. 
Appendix A. Table presenting the effects of time and state on detection probability ( $p$ ), and of state on the probabilities of survival $(S)$, breeding $(\beta)$, breeding successfully $(\gamma)$, and successfully raising two chicks $(\delta)$ in South Polar Skuas and Brown Skuas.

South Polar Skuas

Hypothesis $(S, \beta, \gamma$ and $\Delta$ are state-dependent)

$\begin{array}{cccc}\text { \# Model Rank Deviance } & \Delta \text { AICc } \\ 4 & 18 & 1537.02 & 0 \\ 3 & 20 & 1537.02 & 4.37 \\ 2 & 28 & 1521.37 & 6.64 \\ 5 & 17 & 1550.60 & 11.41 \\ 1 & 52 & 1505.33 & 48.71\end{array}$

$p$ differs between NB and B

$p$ isstate-dependent

$p$ is time-dependent and state-dependent

$p$ is constant

$p$ is time-dependent and state-dependent with an interaction time $\mathrm{x}$ states

Hypothesis ( $p$ differs between NB and B)

\section{$S$ and $\beta$ differ between NB and B; $\gamma$ and $\Delta$ are constant}

$\beta$ differs between NB and $\mathrm{B} ; S, \gamma$ and $\Delta$ are constant

$\begin{array}{cccc}\mathbf{9} & \mathbf{1 1} & \mathbf{1 5 4 3 . 3 6} & \mathbf{0} \\ 10 & 10 & 1547.54 & 2.07 \\ 7 & 13 & 1541.56 & 2.43 \\ 6 & 15 & 1540.62 & 5.76 \\ 4 & 18 & 1537.02 & 8.64 \\ 8 & 11 & 1560.80 & 17.43\end{array}$

$S$ is state-dependant; $\beta$ differs between NB and $\mathrm{B} ; \gamma$ and $\Delta$ are constant

$S$ and $\beta$ are state-dependant; $\gamma$ and $\Delta$ are constant

$S, \beta$ and $\gamma$ are state-dependant; $\Delta$ is constant

$S$ is state-dependant; $\beta, \gamma$, and $\Delta$ are constant

\section{Brown Skuas}

Hypothesis ( $S, \beta, \gamma$ and $\Delta$ are state-dependent)

$p$ differs between NB and $\mathrm{B}$

$p$ is time-dependent and state-dependent

$p$ is state-dependent

$p$ is time-dependent and state-dependent with an interaction time $\mathrm{x}$ states

$p$ is constant

$\begin{array}{cccc}4 & 18 & 1333.29 & 0 \\ 2 & 28 & 1317.11 & 6.39 \\ 3 & 20 & 1333.29 & 4.42 \\ 1 & 52 & 1295.47 & 44.18 \\ 5 & 17 & 1382.10 & 46.62\end{array}$

Hypothesis ( $p$ differs between NB and B)

\section{$S$ and $\beta$ differ between NB and B; $\gamma$ and $\Delta$ are constant}

$S, \beta$ and $\gamma$ are state-dependant; $\Delta$ is constant

$S$ is state-dependant; $\beta$ differs between NB and $\mathrm{B} ; \gamma$ and $\Delta$ are constant

$S$ and $\beta$ are state-dependant; $\gamma$ and $\Delta$ are constant

$S, \gamma, \Delta$ are constant; $\beta$ differs between NB and B

$S$ is state-dependant; $\beta, \gamma$ and $\Delta$ are constant

$\begin{array}{cccc}\mathbf{9} & \mathbf{1 1} & \mathbf{1 3 4 4 . 8 0} & \mathbf{0} \\ 4 & 18 & 1333.29 & 3.60 \\ 7 & 13 & 1343.80 & 3.26 \\ 6 & 15 & 1340.03 & 3.81 \\ 10 & 10 & 1351.77 & 4.86 \\ 8 & 11 & 1399.25 & 54.46\end{array}$

